\title{
Equal Probability Sampling Method
}

National Cancer Institute

\section{Source}

National Cancer Institute. Equal Probability Sampling Method. NCI Thesaurus. Code C71517.

A random process used to select a study population in which each participant has an equal chance of being chosen. 